Société d'histoire de la révolution de 1848 et des

révolutions du XIXe siècle

$46 \mid 2013$

L'espace du politique en Allemagne au XIX' siècle

\title{
Pierre Lévêque, Souvenirs du vingtième siècle
}

Collection Graveurs de mémoire, Paris, L'Harmattan, 2012, 2 tomes tome I : Jeunesse et formation d'un historien (1927-1963), 243 p. ISBN : 978-2-296-99636-6. 25 euros - tome II : Carrière universitaire et action politique (de 1963 à nos jours), 221 p. ISBN : 978-2-296-99637-3. 23 euros

\section{Christophe Voilliot}

\section{(Q) OpenEdition}

Édition électronique

URL : http://journals.openedition.org/rh19/4517

DOI : 10.4000/rh19.4517

ISSN : $1777-5329$

Éditeur

La Société de 1848

Édition imprimée

Date de publication : 1 juin 2013

Pagination : 234-235

ISSN : 1265-1354

Référence électronique

Christophe Voilliot, "Pierre Lévêque, Souvenirs du vingtième siècle ", Revue d'histoire du XIXe siècle [En ligne], 46 | 2013, mis en ligne le 13 janvier 2014, consulté le 22 septembre 2020. URL : http:// journals.openedition.org/rh19/4517; DOl : https://doi.org/10.4000/rh19.4517

Ce document a été généré automatiquement le 22 septembre 2020

Tous droits réservés 


\section{Pierre Lévêque, Souvenirs $d u$ vingtième siècle}

Collection Graveurs de mémoire, Paris, L'Harmattan, 2012, 2 tomes tome I : Jeunesse et formation d'un historien (1927-1963), 243 p. ISBN : 978-2-296-99636-6. 25 euros - tome II : Carrière universitaire et action politique (de 1963 à nos jours), 221 p. ISBN : 978-2-296-99637-3. 23 euros

\section{Christophe Voilliot}

\section{RÉFÉRENCE}

Pierre Lévêque, Souvenirs du vingtième siècle, collection Graveurs de mémoire, Paris, L'Harmattan, 2012, 2 tomes - tome I : Jeunesse et formation d'un historien (1927-1963), 243 p. ISBN : 978-2-296-99636-6. 25 euros - tome II : Carrière universitaire et action politique (de 1963 à nos jours), 221 p. ISBN : 978-2-296-99637-3. 23 euros

1 Pierre Lévêque a décidé de publier sous la forme classique de "souvenirs » un texte initialement destiné à ses enfants afin, comme il s'en explique dans son avant-propos, de ne pas produire un "témoignage incomplet » sur les épisodes de sa vie. Ces deux volumes sont d'une lecture plaisante, le style alerte de l'auteur lui permet d'évoquer avec une précision remarquable aussi bien les épisodes de sa vie publique, les étapes de sa carrière universitaire que les épreuves qu'il a dû affronter. Pierre Lévêque pratique l'art du portrait de manière fort démocratique, il s'efforce de n'oublier personne dans les groupes de pairs ou de connaissances qu'il décrit, sans jamais céder à la tentation de mettre en avant ceux que la notoriété a entre-temps comblés. Si l'on ajoute qu'il ne se départit jamais d'une modestie que connaissent tous ceux qui ont eu la chance de le croiser, on aura donc une idée, certes bien imprécise, de la tonalité de l'ouvrage.

2 Il s'agit donc à la fois d'un témoignage, désormais disponible pour les historiens du $\mathrm{xx}^{\mathrm{e}}$ siècle, d'un récit et d'une méditation sur l'engagement des savants dans la vie de la cité. Il est parfois tentant, dans ce type d'entreprise, de proposer au lecteur un fil conducteur rétrospectif qui donne plus de cohérence que nécessaire à une trajectoire 
sociale pour une part soumise à la contingence. Nulle trace d'un tel subterfuge sous la plume de Pierre Lévêque car, n'ayant jamais quitté l'univers de l'enseignement, c'est tout naturellement qu'il (re)donne vie au milieu social, au sens balzacien du terme, qui fut le sien depuis sa prime enfance. De fait, il a très jeune éprouvé les tensions du métier d'enseignant - la soif d'apprendre et de transmettre les connaissances acquises d'un côté, la responsabilité sociale du maître de l'autre - au contact de ses parents en charge des deux classes de l'école mixte du petit village d'Izeure en Saône-et-Loire. De l'école d'Izeure à l'université de Bourgogne, ainsi pourrait-on résumer à grand trait son parcours. Comment en effet ne pas être convaincu de la capacité d'attraction de ce métier d'enseignant lorsque Pierre Lévêque évoque la manière dont il a refusé, lors des élections législatives de 1967 en Côte d'Or, une investiture partisane qui aurait pu faire de lui un parlementaire et un professionnel de la politique (tome 2, p. 47-48) ? Et pourtant, on ne peut pas dire que Pierre Lévêque n'ait pas consacré beaucoup de temps et d'énergie à la vie politique, souvent avec détermination, toujours avec conviction. On lira ainsi avec attention les pages (tome 1, p. 155-192) où il relate ses pratiques militantes - il est alors membre du PCF - lorsque, jeune agrégé d'histoire, il est affecté au lycée Bartholdi de Colmar. Homme de gauche, défenseur d'un socialisme démocratique, il est tentant de lire l'engagement politique de Pierre Lévêque au regard de cette imprégnation précoce propre au monde enseignant. Les conversations politiques de son entourage familial n'étaient pas dissimulées au jeune enfant qu'il fut dans les années trente. De ces années-là datent d'ailleurs ses "premiers véritables souvenirs politiques» nous dit-il (tome 1, p. 52). Reste l'historien. Ces deux volumes restituent bien entendu l'itinéraire de recherche de l'auteur et notamment la genèse d'une grande thèse dix-neuvièmiste sur La Bourgogne de la monarchie de Juillet au Second Empire $^{1}$, depuis les hésitations initiales sur la définition du sujet jusqu'à la soutenance en Sorbonne en 1977 et la publication à l'orée des années $1980^{2}$. S'il est inévitable que le travail d'un chercheur finisse par se résumer à sa bibliographie, ces souvenirs en conserveront aussi l'inspiration humaniste, au grand plaisir des lecteurs et des amis de Pierre Lévêque, à n'en pas douter.

\section{NOTES}

1. Sur cette historiographie, cf. "Les Frances du XIX " », in Sylvie Aprile, La révolution inachevée, 1815-1870, Paris, Belin, 2010, p. 539-540.

2. Pierre Lévêque, Une société provinciale. La Bourgogne sous la monarchie de Juillet, Paris, Éditions de l'EHESS, 1983 ; Une société en crise. La Bourgogne au milieu du XIX ${ }^{\mathrm{e}}$ siècle, 1846-1852, Paris, Éditions de l'EHESS, 1983. 